\title{
A new method of culturing rat bone marrow endothelial progenitor cells in vitro
}

\author{
Zhaohong Kong ${ }^{1}$, Meixin Chen ${ }^{2}$, Jian Jiang $^{1}$, Jiang Zhu $^{3}$, Yumin Liu ${ }^{2}$ \\ ${ }^{1}$ Department of Neurology, Renmin Hospital of Wuhan University, Wuhan, China; ${ }^{2}$ Department of Neurology, Zhongnan Hospital of Wuhan \\ University, Wuhan, China; ${ }^{3}$ Department of Neurology, The First Hospital of Yulin, Yulin, China \\ Contributions: (I) Conception and design: Z Kong, M Chen, J Zhu, Y Liu; (II) Administrative support: J Jiang, J Zhu, Y Liu; (III) Provision of study \\ materials or patients: Z Kong, M Chen, J Jiang; (IV) Collection and assembly of data: Z Kong, M Chen, J Zhu; (V) Data analysis and interpretation: \\ Z Kong, M Chen, J Zhu, Y Liu; (VI) Manuscript writing: All authors; (VII) Final approval of manuscript: All authors. \\ Correspondence to: Jiang Zhu, MD, PhD. Department of Neurology, The First Hospital of Yulin, Shaanxi, China. Email: zhenbeitai@163.com; Yumin \\ Liu, MD, PhD. Department of Neurology, Wuhan University Zhongnan Hospital, Wuhan 430071, China. Email: WB001792@whu.edu.cn.
}

Background: Endothelial progenitor cells (EPCs) play an important role in the re-endothelialization of ischemic cerebrovascular disease. However, the current acquisition method has some deficiencies. This study aimed to design a new and practical method for obtaining EPCs.

Methods: Bone marrow was obtained autologously from the right tibia of living rats. Briefly, the right tibia bone was carefully exposed and two holes $(1 \mathrm{~mm}$ in diameter) were made in the tuberosity and lower one-third of the tibia, respectively. A PE-50 catheter and syringe $(5 \mathrm{~mL})$ were inserted through the holes to aspirate the bone marrow. Bone marrow mononuclear cells (BMMCs) were isolated by density-gradient centrifugation with Ficoll and counted. Adherent cell culture continued for 2 weeks, and the medium was replaced every 3 days.

Results: During the first days of culture, adherent cells formed a monolayer, consisting predominantly of small-sized cells. Single large cells with endothelial morphology were observed. On day 4, the nonadherent cells were removed, and the adherent cells were left for further culture. On day 6-7, a proliferating population of round cells formed clusters in the culture chamber, and morphological analysis revealed a homogeneous population of colony-forming units (CFUs). Large, flat cells with endothelial morphology sprouted from the CFUs, which had nearly disappeared by day 14 of culture. The adherent cells were positive for CD133 and vascular endothelial growth factor receptor 2 (VEGFR2), internalized acetylated low-density lipoprotein, and bound ulex europaeus-agglutinin-I, but were negative for CD45, which correlated with the endothelial morphology and ability to form capillaries of EPCs.

Conclusions: Our results are direct evidence that mononuclear cells (MCS) from living rat bone marrow can be used to culture EPCs in vitro under certain culture conditions, providing a new method for the further study of autologous EPC transplantation.

Keywords: Bone marrow; cell culture; endothelial progenitor cells (EPCs); rats

Submitted May 28, 2020. Accepted for publication Aug 30, 2020.

doi: $10.21037 / \mathrm{cdt}-20-536$

View this article at: http://dx.doi.org/10.21037/cdt-20-536

\section{Introduction}

Cell therapy has opened up a new avenue of treatment for ischemic disease (1-3). Endothelial progenitor cells (EPCs) are among the most widely used stem cells, owing to their powerful potential for proliferation and differentiation to vascular ECs (4). The origin of EPCs is presumed to be the same as that of hematopoietic stem cells (HSCs), the progenitor cells of which arise in the embryonic mesodermal blood island (5). Because of their special origin, 
EPCs and HSCs share certain antigenic determinants, including CD133 (AC133), CD34, vascular endothelial growth factor receptor 2 (VEGFR2, also called Flk-1 and KDR in mice and humans, respectively), Tie-2, c-Kit, and Sca-1 (6). According to the previous study, CD133 is a highly conserved antigen expressed on some stem cells, and has been proved to be the main surface marker distinguishing EPCs from ECs (7-9). After the differentiation step (4), EPCs have the same markers as ECs, such as vascular endothelial cadherin, Tie-2, and VEGFR2, along with the EC functions of releasing nitric oxide (NO), forming capillaries, internalizing Ac-LDL, and binding lectins such as ulex europaeus-agglutinin-I (UEA-I). Thus, CD133+/VEGFR2 + cells with the same functions as ECs were most likely represent EPCs (10). Despite the uncertainty regarding their origin, phenotype, and therapeutic viability, great interest surrounds the harnessing of EPCs to promote vascular regeneration.

At the same time, there is great academic debate. Firstly, there is no standardization of cell surface markers or culture protocols for the production of EPCs for therapeutic intervention (11). Secondly, some experts have reported that EPCs originate from the bone marrow, mobilize in response to ischemia, and home in to sites of vascular injury. However, recent research discovered that endogenous neovascularization is driven by tissue-resident EPCs with no direct contribution from bone marrow cells $(12,13)$.

The basis of the debate may be related to the different sources of stem cells used in interventions. Previous studies have shown that bone marrow EPCs are associated with more consistent benefits than circulating EPCs (12). However, the current methods of EPC culture mainly use umbilical peripheral venous blood, and many deficiencies exist. For example, the success rate with peripheral blood $(\mathrm{PB})$ is low, the mortality rate is extremely high, and umbilical peripheral venous blood is difficult to obtain. Moreover, dead rats have traditionally served as the bone marrow source, which makes follow-up autotransplantation research challenging to complete. Currently, there is little direct evidence on whether EPCs can be induced and differentiated in vitro from living rat bone marrow.

In the present study, we used unmanipulated rat bone marrow mononuclear cells (BMMCs) as the starting material for inducing EPC culture in vitro. We identified EPCs by their functional and phenotypic characteristics, and explored the requirements for further study of autologous EPC transplantation for cerebral ischemia in rats.
We present the study in accordance with the ARRIVE reporting checklist (available at http://dx.doi.org/10.21037/ cdt-20-536).

\section{Methods}

\section{Animals}

Twenty adult male Sprague Dawley (SD) rats, weighing between 250 and $280 \mathrm{~g}$, were obtained from Wuhan University Experiment Animal Center and used in all experiments. All experimental procedures were approved by the Research Animal Resources and Care Committee of Hubei Province, China (No. 50,2005), in compliance with the Laboratory Animal regulation of China [2001] for the care and use of animals.

\section{BMMC acquisition}

Bone marrow was obtained autologously from the right tibia of each animal. First, the rats were anesthetized with $10 \%$ chloral hydrate intraperitoneal injection $(0.035 \mathrm{~mL} / \mathrm{kg})$. Under aseptic conditions, the right tibia was fully exposed and prepared for drilling. Two holes $(1 \mathrm{~mm}$ in diameter) were made in the tuberosity and lower one-third of the tibia, respectively. A PE-50 catheter was inserted through the hole in the tuberosity, and a syringe $(5 \mathrm{~mL})$ was inserted through the lower tibial hole to aspirate the bone marrow as follows. Phosphate Buffered Saline (PBS) was infused through the PE-50 catheter by one researcher, while a second researcher aspirated approximately $5 \mathrm{~mL}$ of bone marrow with the syringe. The incision was sutured and the rats were allowed to recover.

Mononuclear cells (MCS) were isolated from the bone marrow by density-gradient centrifugation $(14,15)$ (FicollHypaque, LTS1083; TBD Science, Tianjin, China). The harvested cells were supplemented with M199 medium (Sigma-Aldrich, USA), containing $10 \mathrm{ng} / \mathrm{mL}$ VEGF (PeproTech Inc., Rocky Hill, CT, USA), $1 \mathrm{ng} / \mathrm{mL}$ basic fibroblast growth factor (b-FGF, PeproTech Inc.), $1 \mathrm{ng} / \mathrm{mL}$ epidermal growth factor (EGF, PeproTech Inc.), 20\% fetal bovine serum (FBS, Invitrogen), heparin, penicillin, and streptomycin.

\section{Induced culture of bone-marrow EPCs}

Cell suspensions of each rat were plated on 24-well culture plates with culture wells pretreated with human fibrolectin 
(hFN, Chemicon International, Temecula, CA, USA). The suspended cells were plated at three different densities: $2 \times 10^{6}, 3 \times 10^{6}$, and $4 \times 10^{6}$ cells/well; each density group comprised of 3 wells from 6 rats. The cells were incubated at $37^{\circ} \mathrm{C}$ with $5 \% \mathrm{CO}_{2}$ and left undisturbed for 4 days $(14,15)$. The medium was completely replaced every 3 days to remove nonadherent cells. The induced culture of adherent cells continued for 2 weeks. On days 7, 10, and 14 of culture, each well was observed under $\times 400$ magnification, 5 randomly chosen microscopic fields were photographed, and the number of adherent cells and CFUs in each highpower field were counted by photo software (HPIAS2000). The averages of five fields in each well were compared to select the optimal density.

After choosing the optimal density, another five rats were euthanized to harvest BMMCs, and the suspended cells were plated at the optimal density on a 24-well culture plate. Each well contained a previously placed coverslip that was coated with human fibrolectin (hFN). After 14 days of induced culture, the coverslips with adherent cells were used for the identification of EPCs.

\section{Immunophenotyping}

Immunocytochemistry was performed according to standard protocols (16) and the manufacturers' instructions. EPCs were fixed with $4 \%$ paraformaldehyde (PFA, SigmaAldrich) for $20 \mathrm{~min}$ at $4{ }^{\circ} \mathrm{C}$, and washed in PBS. The fixed EPCs were identified by their expression of CD133 and VEGFR2 using immunohistochemistry. We used primary rabbit polyclonal antibodies against rat CD133 (BioTech, Beijing, China) and rat VEGFR2 (Boster, Wuhan, China). In the preliminary step, endogenous peroxidase activity was blocked with $3 \% \mathrm{H}_{2} \mathrm{O}_{2}$ for $10 \mathrm{~min}$ at $37{ }^{\circ} \mathrm{C}$, and the cells were rinsed in distilled water. Antigen was retrieved with $0.1 \%$ trypsin solution for $10 \mathrm{~min}$, the cells were rinsed in PBS, $5 \%$ bovine serum albumin (Boster, Wuhan, China) was applied for blocking, and 15 min later the excess solution was tapped. The cells were incubated overnight with 1:10 ratio $\mu \mathrm{g} / \mathrm{mL}$ primary antibody in $\mathrm{PBS}$ at $4{ }^{\circ} \mathrm{C}$, then rinsed in PBS. We then proceeded with the biotinylated second antibody (goat anti-rabbit IgG) and streptavidin biotin peroxidase complex (SABC) following the instructions of the rat SABC kit (SA1022, Boster). Following the manufacturer's directions 3,3'-diaminobenzidine (DAB) was used for color development (ZSGB-BIO, Beijing, China), and the nuclei were counterstained with hematoxylin.

\section{Internalization of Dil-Ac-LDL and binding of FITC-UEA-I}

To assess Ac-LDL internalization and UEA-I binding, we used Dil-labeled Ac-LDL (Dil-Ac-LDL, Biomedical Technologies, Inc., Stoughton, MA, USA) and fluorescein isocyanate (FITC)-labeled UEA-I (FITC-UEA-I, SigmaAldrich), as previously described $(17,18)$. The samples were observed using confocal laser scanning microscopy (Leica TCS SP2 AOBS MP, Germany). On day 14, live cells were incubated with $10 \mu \mathrm{g} / \mathrm{mL}$ Dil-Ac-LDL in M199 media (without other additions) for 4 hours at $37^{\circ} \mathrm{C}$, then the medium containing Dil-Ac-LDL was removed and the cells were washed several times with PBS. Next, the cells were fixed with $4 \%$ PFA for $20 \mathrm{~min}$ at $4{ }^{\circ} \mathrm{C}$, washed several times with PBS, and then incubated with $10 \mu \mathrm{g} / \mathrm{mL}$ FITC-UEA-I in PBS for 1 hour at $37^{\circ} \mathrm{C}$. Finally, the cells were washed several times with PBS and examined using a confocal laser scanning microscopy system (LCS Lite). All steps of the procedure were performed in the dark.

\section{Flow cytometry}

Cells were cultured for 9 days, then digested and collected with $0.25 \%$ (mass concentration) pancreatin and washed twice with PBS. The cells were set up in single standard tubes No. 1, No. 2, and No. 3, to which was human CD34PE, CD45-PE, and anti-CD133 was added, respectively, before incubation at $4{ }^{\circ} \mathrm{C}$ in the dark for $30 \mathrm{~min}$. After twice washing with PBS, single standard tubes No. 1 and No. 2 were tested on the flow cytometer; single standard tube No. 3 had a second antibody added and FITC, and was incubated at $4{ }^{\circ} \mathrm{C}$ in the dark for $30 \mathrm{~min}$. In the negative control group, PBS was used to replace the cells, while in the blank control group, PBS was used to replace the first antibody. The positive expression rates of CD34, CD13, CD45, and CD44 in EPCs were detected.

\section{Statistical analysis}

Data are presented as mean \pm standard deviation. Statistical evaluation of the data was by one-way analysis of variance (ANOVA) for intergroup comparison analysis, and bivariate correlation analysis for the relevant factors. All statistical 


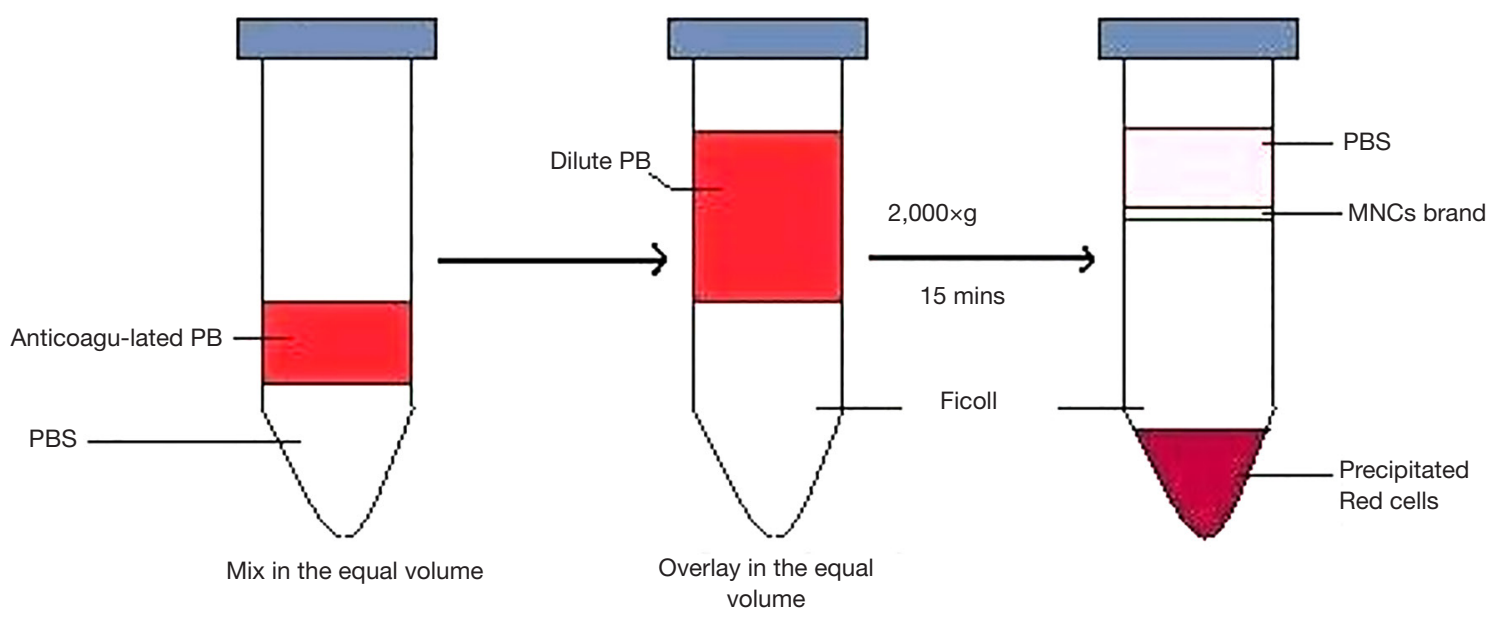

B
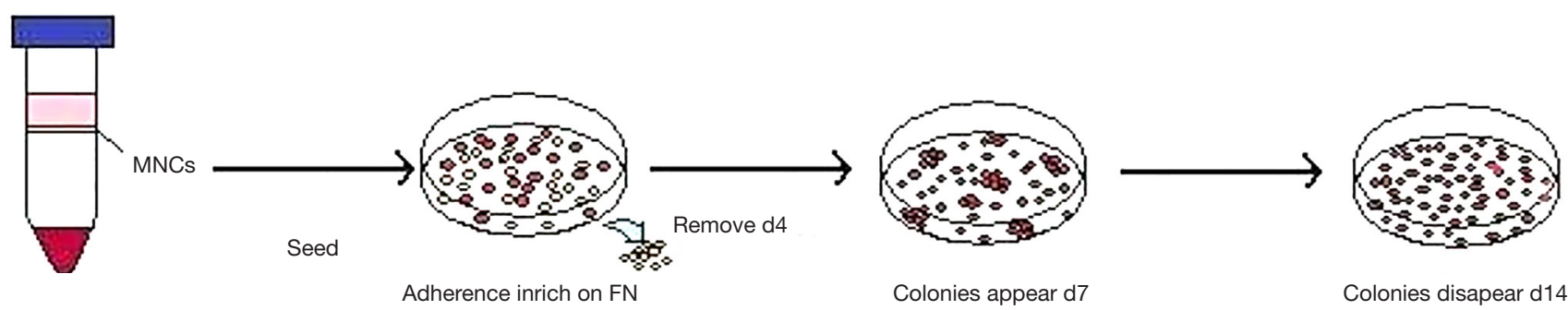

Figure 1 Culture of endothelial progenitor cells (EPCs) from rat bone marrow. (A) Ficoll-Hypaque density-gradient configuration. (I) Diluted anticoagulated bone marrow in equal volumes. (II) Overlaid diluted bone marrow above equal volume of Ficoll-Hypaque, centrifuged for 15 min at $4^{\circ} \mathrm{C}$, at 2,000 revolutions per minute $(\times \mathrm{g})$. Red blood cells deposit and MNCs are suspended in the interface between PBS and FicollHypaque. (B) Culture of EPCs from rat bone marrow. Yellow cells are nonadherent cells and red cells are adherent cells. FN, fibronectin; PBS, phosphate-buffered saline.

analyses were computed by SPSS 19.0 (IBM Corp, USA).

\section{Results}

\section{Morphology of the cultured cells}

BMMNCs were harvested and seeded onto hFN-coated culture plates in EPC selection medium, which contained given FBS and growth factors to promote EPC growth (Figure 1A). On day 4, the nonadherent cells were removed, and the adherent cells were left for further culture (Figure $1 \mathrm{~B}$ ). During the first days of culture, adherent cells formed a monolayer, consisting of predominantly of small-sized cells. Single large cells with endothelial morphology were observed (Figure 2A,B). No significant proliferation was noted during this culture period. On day $6-7$, a proliferating population of round cells occurred, forming clusters in the culture chamber (Figure 2C,D).
Morphological analysis of the cell clusters revealed a homogeneous cell population forming CFUs, and large flat cells with endothelial morphology sprouting from the CFUs (Figure 2E,F).

\section{Adherent cells and CFUs of different plating density groups}

During the 2-week culture, the harvested adherent cells grew, but the three plating density groups differed. After 10 days of culture, the adherent cell count of group A $\left(2 \times 10^{6}\right.$ cells/well) was less than groups B and C, but group B $\left(3 \times 10^{6}\right.$ cells/well $)$ and $C\left(4 \times 10^{6}\right.$ cells/well $)$ showed no significant differences on days 10 and $14(\mathrm{P}>0.05$ group $\mathrm{C}$ vs. group B, one-way ANOVA) (Figure $3 A$ ). The CFU count of group A was also less than the others, but groups $\mathrm{B}$ and $\mathrm{C}$ showed no significant differences on days 7 and 10 ( $\mathrm{P}>0.05$ group $\mathrm{C} v$ s. group $\mathrm{B}$, one-way ANOVA). Of the 

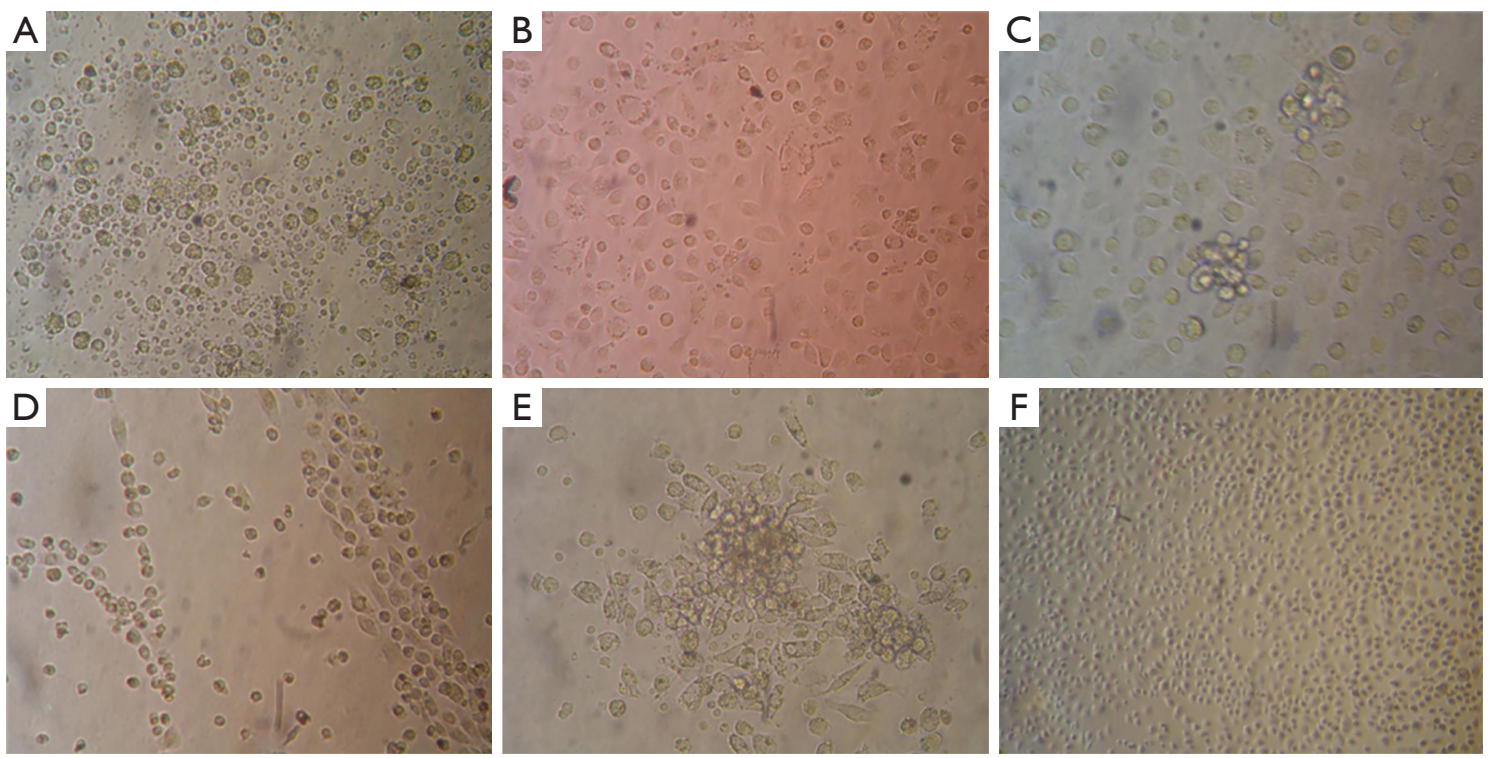

Figure 2 Morphological observation of cultured EPCs. Representative phase-contrast photomicrographs of EPCs. (A) On day 4 of culture, adherent cells have a round shape $(\times 400)$. (B) On day 6 of culture, some adherent cells have extended into a spindle shape $(x 400)$. (C) On day 7 of culture, some adherent cells have proliferated into CFUs ( $\times 500)$. (D) On day 10 of culture, cells had heterogeneous shapes, and some of the spindle-shaped cells had linked together, forming a tube $(\times 400)$. (E) On day 10 of culture, adherent cells had proliferated and differentiated, with some elongated cells sprouting from the central core of CFUs $(\times 400)$. (F) On day 14 of culture, the CFUs had nearly disappeared, and the majority of the adherent cells had differentiated to spindle-shaped cells, with a "cobblestone" appearance $(\times 250)$. CFU, colony-forming unit; EPC, endothelial progenitor cell.

3 testing time points, day 10 had the maximum number of CFUs, and by day 14, the CFUs in all density groups had disappeared (Figure 3B). These results indicated that $3 \times 10^{6}$ cells/well was the optimal plating density under our experimental conditions. Analysis of the correlation of adherent cells and CFUs of all samples on day 10 showed the two variables to have a satisfactory correlation $(\mathrm{r}=0.829$, $\mathrm{P}=0.000$, bivariate correlation analysis) (Figure 3C).

\section{Immunocytochemical analysis of BMMNCs}

After 12 days of primary culture, the MNCs had almost fused and were arranged in a typical cobblestone-like pattern. The number of cells could be expanded to approximately 106. The results of immunohistochemistry showed that CD34 (86.36 \pm 5.12$) \%$, CD45 $(30.25 \pm 4.62) \%$, and CD133 (19.72 \pm 5.20$) \%$ stained positive, and the cytoplasm was brown (Figure 4). CD44 was negative, indicating that the cells detected were not bone marrow mesenchymal stem cells (BMMNCs), that CD44 had been labeled, and that cell purity was high.

\section{Internalization of Dil-Ac-LDL and binding of FITC- UEA-I}

On day 12 of induction culture in vitro, laser confocal microscopy showed that the cultured cells had the ability to phagocytize Dil-Ac-IDL and FITC-UEA-I: the cells combined with FITC-UEA-I showed green fluorescence, while the cells that had ingested Dil-Ac-ldl showed red fluorescence. Laser confocal image analysis was used for fluorescence superposition, and the results showed that the positive rate of double fluorescence was $65.01 \pm 12.50$ (Figure 5), indicating that cell activity was strong, which would meet the needs of future experiments.

\section{Flow cytometric analysis of BMMNCs differentiating into EPCs}

The presence of CD13 and CD45, and a subsequent loss of CD34, suggests that EPCs have differentiated into mature ECs. CD44 is a unique marker of BMMSCs, which are easily confused with EPCs. On day 12 of induction culture in vitro, the results of flow cytometry showed that the cells 

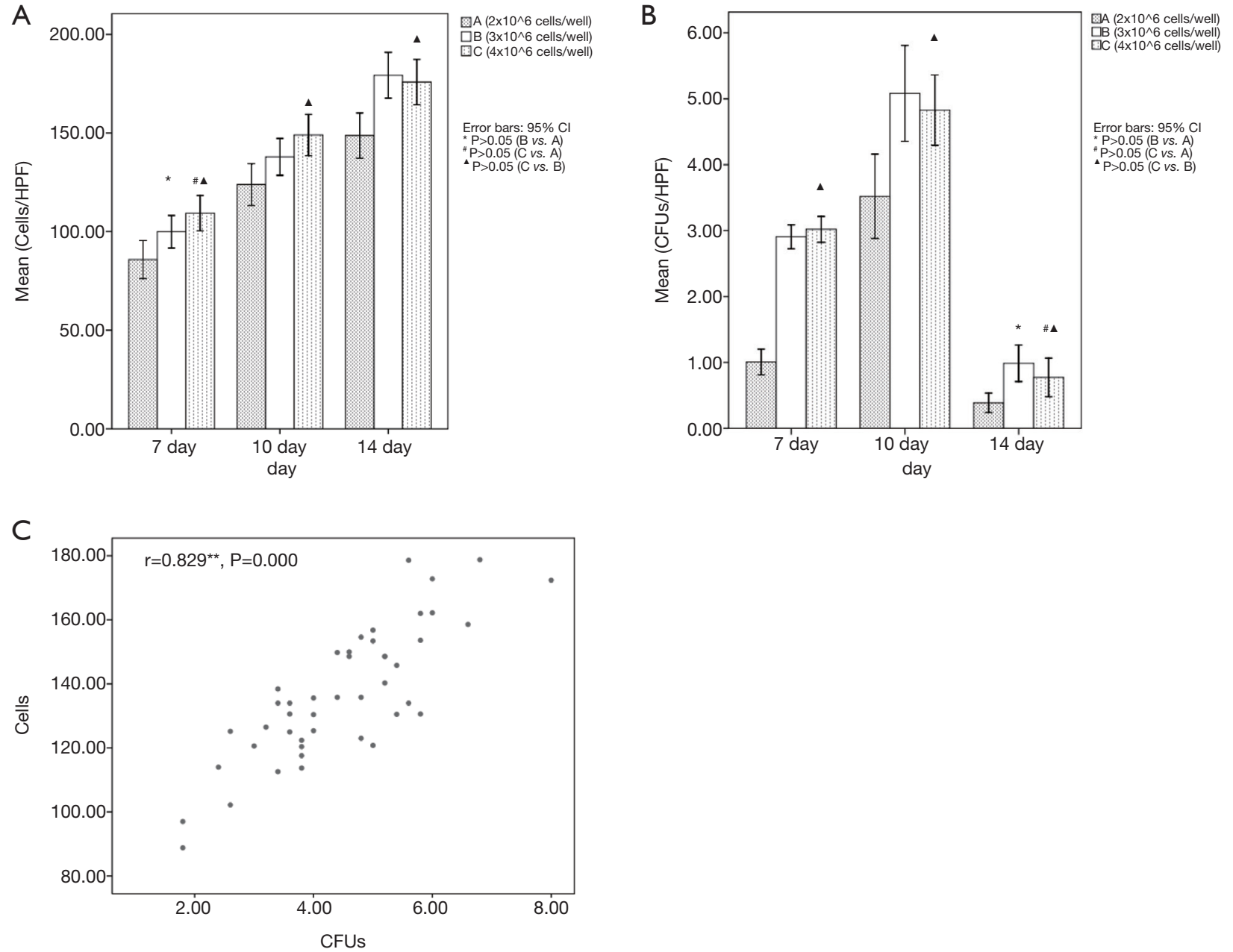

Figure 3 Adherent cells and CFU count at different plating densities. (A,B) The counts of adherent cells and CFUs in three groups at different plating densities. *, $\mathrm{P}>0.05$ comparing group $\mathrm{B}$ with group $\mathrm{A} ;{ }^{*}, \mathrm{P}>0.05$ comparing group $\mathrm{C}$ with group $\mathrm{A} ;{ }^{\boldsymbol{A}}, \mathrm{P}>0.05$ comparing group C with group B (one-way ANOVA). (C) Correlation of adherent cells and CFUs in total samples on day 10, r=0.829, $\mathrm{P}=0.000$ (bivariate correlation analysis). CFU, colony-forming unit.
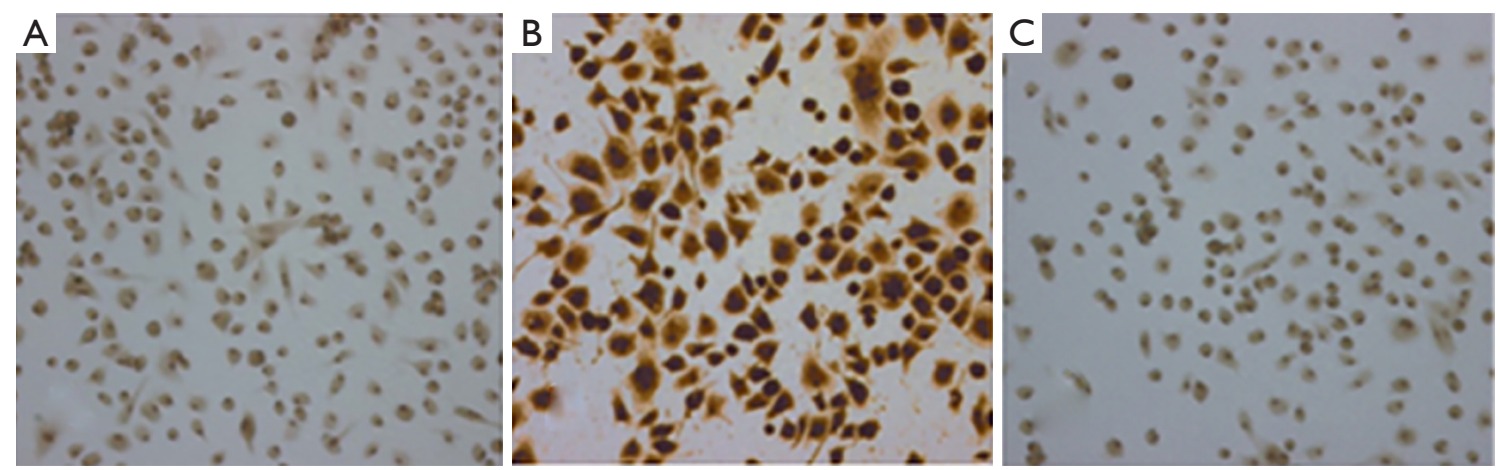

Figure 4 Immunocytochemical analysis of BMMNCs. After 14 days of culture, BMMNCs revealed expression of rat stem cell markers ( $\times 400)$. (A) CD34 is positive and the cytoplasm is brown (86.36 \pm 5.12$)$; (B) CD45 is positive (30.25 \pm 4.62$)$; (C) CD133 is positive (19.72 \pm 5.20 ). 

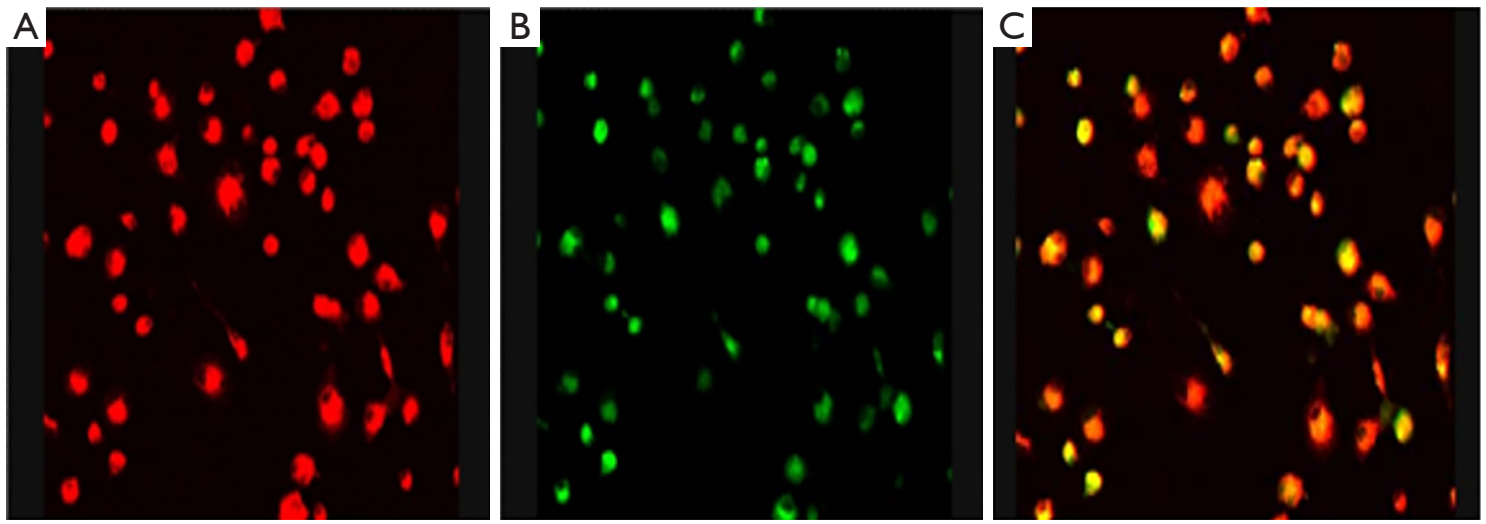

Figure 5 Internalization of Dil-Ac-LDL and binding of FITC-UEA-I. Imaging under $\times 400$ magnification. (A) Adherent cells have internalized Dil-Ac-LDL presenting red fluorescence $(\times 400)$. (B) Adherent cells have bound FITC-UEA-I presenting green fluorescence ( $\times 400)$. (C) The majority of adherent cells are both Dil-Ac-LDL and lectin positive (yellow overlap, $\times 400 ; 56.9 \% \pm 4.2 \%, \mathrm{n}=8$ of 3 highpower fields per section). FITC, fluorescein isocyanate; UEA-I, ulex europaeus-agglutinin-I.
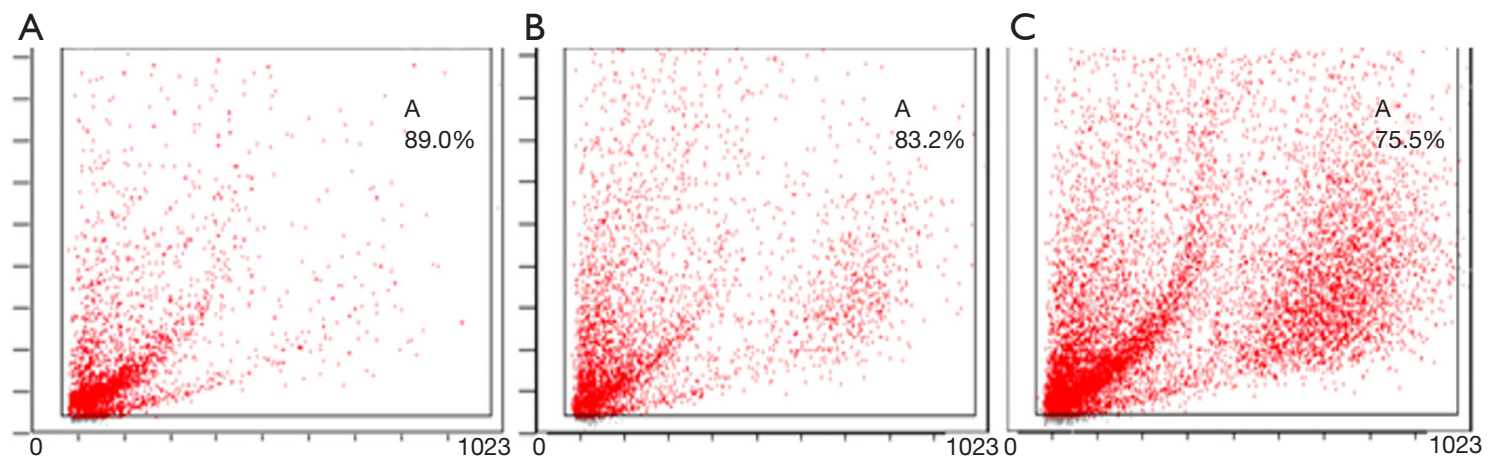

Figure 6 Flow cytometry analysis of BMMNCs differentiating into EPCs. After 12 days in vitro, the results of flow cytometry show that: (A) CD34 is positive (89.0\%); (B) CD45 is positive (83.2\%); (C) CD133 is positive (75.5\%). BMMNCs, bone-marrow mononuclear cells; EPCs, endothelial progenitor cells.

were positive for CD34, CD45, and CD133, but negative for $\mathrm{CD} 44$. The results also discovered that the positive rate of double fluorescence in the cells were $89.0 \%$ for CD34, $83.2 \%$ for CD 45 and $75.5 \%$ for CD133, respectively. Figure 6 suggesting that cell activity was strong and could meet the needs of future experiments.

\section{Discussion}

EPCs can localize in the bone marrow and $\mathrm{PB}$ or can reside in the arterial wall $(7,19,20)$. An earlier study showed that EPCs are a small subpopulation $(<0.05 \%)$ of the leukocyte fraction of bone marrow-derived mononuclear hematopoietic cells in adults humans (21). Experimental data support that EPCs can be induced and differentiated from rat bone marrow; therefore, we separated EPCs from uncommitted MNCs utilizing the adherent properties of endothelial lineage cells. Being stimulated by some earlyacting and endothelial lineage-restricted growth factors (i.e., VEGF, b-FGF, and EGF), the progenitor cells that were initially separated were induced to proliferate and trigger differentiation into EPCs.

EPCs are of great interest because of their potential in cell therapy for vascular diseases and ischemic conditions (22-24). Recent advances in stem cell technology have enabled researchers to separate EPCs from stem cells and other precursor populations. However, most of these studies mainly used PB EPCs (14). PB EPCs show high mortality and low successful culture rates, which has restricted research into autologous transplantation in rats. In the present study, we used rat bone marrow as the source of MNCs, and identified EPCs by their phenotypic 
characteristics and function.

EPCs can be enriched by antigen-positive selection from among the MNCs of bone marrow or PB cells. CD133, VEGFR2, CD34 and other factors have been reported as antigens for EPC selection $(7,19)$. We also explored EC functions such as releasing $\mathrm{NO}$, forming capillaries, internalizing Ac-LDL, and binding lectins such as UEA-I $(17,18)$. Thus, we determined that CD133+/VEGFR2+ cells with the same function as ECs most likely represent EPCs $(10,17,18)$.

The number of positive cells, however, was very limited, and single-population culture is not always successful. For this reason, we used whole MNC culture to augment the differentiation and proliferation of EPCs under ECspecific culture conditions. As reported in previous studies, various differentiation techniques to induce EPC differentiation have been explored $(1,18,19)$. Often, a combination of differentiation stimuli, including cytokines, extracellular matrix (ECM) coatings, seeding density, and mechanical stimulation improves the yield, quality, and differentiated state. Almost all studies have induced EPCs from adult stem or progenitor cells using VEGF alone or in combination with other growth factors, so VEGF is considered necessary. The effects of other growth factors in addition to VEGF have not been fully compared with those of VEGF alone (25-27). Different studies have used different VEGF concentrations, ranging from 5 to $100 \mathrm{ng} / \mathrm{mL}$; therefore, the effect of a graded concentration has not been studied extensively. ECM is critical in all aspects of vascular biology, because it supports the adhesion, migration, proliferation, and survival of ECs, and gives cues for capillary morphogenesis and neovessel stability and maturation (28). Fibronectin (FN) is used in EPCinduced culture, because it has been proven to significantly enhance VEGF-induced differentiation of EPCs $(29,30)$. As another culture parameter, the seeding density can influence the survival and proliferation of EPCs. A study of ESCs hypothesized that cell-cell contact and membraneassociated factors are important for the proliferation of stem cells, and that the appropriate microenvironment is essential (30). Our results suggest that VEGF used in combination with other growth factors (b-FGF and EGF) supports EPC growth and differentiation into ECs. From our observations, compared with culture conditions without growth factor, the combination of low-concentration growth factors can significantly enhance adherent cells' survival and differentiation. Pretreating culture wells with FN noticeably enhanced the adhesion and differentiation of cells. Additionally, because the adherent cells were more likely to gather on the glass coverslips, we suggest that glass culture dishes might be most suitable.

We compared three different seeding densities of MNCs in this experiment, and discovered that $3 \times 10^{6}$ cells/well was the optimal plating density under our experimental conditions. EPCs cultured in vitro are adherent cells; their survival depends on the seeding density but they can be contact inhibited, which means a density that is too high or too low might decrease their survival and differentiation.

Because identification of EPCs remains controversial, the cells in different reports may not have the same phenotype. Each group has named the identified EPCs differently, according to their markers, adding to the confusion of EPC nomenclature. In our experiment, the adherent cells were positive for CD133 and VEGFR2, internalized DilAc-LDL and bound FITC-UEA-I, which represented EC morphology and the ability to form capillaries, suggesting EPCs. Further research is needed to understand the mechanism of action of growth factors in EPC-induced culture.

\section{Conclusions}

This study provides strong evidence that EPCs can be induced from BMMCS using growth factor-supplemented medium under appropriate culture conditions. However, further study is needed to enable autologous bone marrow EPC transplantation in cerebral ischemic rats.

\section{Acknowledgments}

Funding: This work was supported by the Wu Jieping Medical Foundation to Dr. ZK (number: 320.6750.1909223) and a National Natural Science Foundation grant to Dr. YL (number: 81371273).

\section{Footnote}

Reporting Checklist: The authors present the study in accordance with the ARRIVE reporting checklist. Available at http://dx.doi.org/10.21037/cdt-20-536

Data Sharing Statement: Available at http://dx.doi. org/10.21037/cdt-20-536

Peer Review File: Available at http://dx.doi.org/10.21037/ cdt-20-536 
Conflicts of Interest: All authors have completed the ICMJE uniform disclosure form (available at http://dx.doi. org/10.21037/cdt-20-536). JJ reports grants from National Natural Science Foundation grant, grants from Wu Jieping Medical Foundation, outside the submitted work; JZ reports grants from National Natural Science Foundation grant, grants from Wu Jieping Medical Foundation, outside the submitted work; MC reports grants from National Natural Science Foundation grant, grants from Wu Jieping Medical Foundation, outside the submitted work; YL reports grants from National Natural Science Foundation grant, grants from Wu Jieping Medical Foundation, outside the submitted work; ZK reports grants from National Natural Science Foundation grant, grants from Wu Jieping Medical Foundation, outside the submitted work. The authors have no other conflicts of interest to declare.

Ethical Statement: The authors are accountable for all aspects of the work by ensuring that questions related to the accuracy or integrity of any part of the work are appropriately investigated and resolved. All experimental procedures were approved by the Research Animal Resources and Care Committee of Hubei Province, China (No. 50,2005), in compliance with the Laboratory Animal regulation of China [2001] for the care and use of animals.

Open Access Statement: This is an Open Access article distributed in accordance with the Creative Commons Attribution-NonCommercial-NoDerivs 4.0 International License (CC BY-NC-ND 4.0), which permits the noncommercial replication and distribution of the article with the strict proviso that no changes or edits are made and the original work is properly cited (including links to both the formal publication through the relevant DOI and the license). See: https://creativecommons.org/licenses/by-nc-nd/4.0/.

\section{References}

1. Bayraktutan U. Endothelial progenitor cells: Potential novel therapeutics for ischaemic stroke. Pharmacol Res 2019;144:181-91.

2. Reid E, Guduric-Fuchs J, O'Neill CL, et al. Preclinical evaluation and optimization of a cell therapy using human cord blood-derived endothelial colony-forming cells for ischemic retinopathies. Stem Cells Transl Med 2018,7:59-67.

3. Ricottini E, Madonna R, Grieco D, et al. Effect of high-dose atorvastatin reload on the release of endothelial progenitor cells in patients on long-term statin treatment who underwent percutaneous coronary intervention (from the ARMYDA-EPC Study). Am J Cardiol 2016;117:165-71.

4. Zammaretti $\mathrm{P}$, Zisch AH. Adult 'endothelial progenitor cells'-Renewing vasculature. Int J Biochem Cell Biol 2005;37:493-503.

5. Castelli G, Parolini I, Cerio AM, et al. Conditioned medium from human umbilical vein endothelial cells markedly improves the proliferation and differentiation of circulating endothelial progenitors. Blood Cells Mol Dis 2016;61:58-65.

6. Fraineau S, Palii CG, McNeill B, et al. Epigenetic activation of pro-angiogenic signaling pathways in human endothelial progenitors increases vasculogenesis. Stem Cell Reports 2017;9:1573-87.

7. Peichev M, Naiyer AJ, Pereira D, et al. Expression of VEGFR-2 and AC133 by circulating human CD34(+) cells identifies a population of functional endothelial precursors. Blood 2000;95:952-8.

8. Schmeisser A, Strasser RH. Phenotypic overlap between hematopoietic cells with suggested angioblastic potential and vascular endothelial cells. J Hematother Stem Cell Res 2002;11:69-79.

9. Rafii S, Lyden D. Therapeutic stem and progenitor cell transplantation for organ vascularization and regeneration. Nat Med 2003;9:702-12.

10. Hristov M, Weber C. Endothelial progenitor cells: characterization, pathophysiology, and possible clinical relevance. J Cell Mol Med 2004;8:498-508.

11. Medina RJ, Barber CL, Sabatier F, et al. Endothelial progenitors: a consensus statement on nomenclature. Stem Cells Transl Med 2017;6:1316-20.

12. Fujisawa T, Tura-Ceide O, Hunter A, et al. Endothelial Progenitor Cells Do Not Originate from the Bone Marrow. Circulation 2019;140:1524-6.

13. Li Z, Solomonidis EG, Meloni M, et al. Single-cell transcriptome analyses reveal novel targets modulating cardiac neovascularization by resident endothelial cells following myocardial infarction. Eur Heart J 2019;40:2507-20.

14. Kamiya $N$, Ueda $M$, Igarashi $H$, et al. Intra-arterial transplantation of bone marrow mononuclear cells immediately after reperfusion decreases brain injury after focal ischemia in rats. Life Sci 2008;83:433-7.

15. Homayouni Moghadam F, Tayebi T, Barzegar K. Differentiation of Rat bone marrow Mesenchymal stem cells into Adipocytes and Cardiomyocytes after treatment 
with platelet lysate. Int J Hematol Oncol Stem Cell Res 2016;10:21-9.

16. Zhang X, Lian W, Lou W, et al. Transcatheter arterial infusion of autologous CD133(+) cells for diabetic peripheralartery disease. Stem Cells Int 2016;2016:6925357.

17. Walenta K, Friedrich EB, Sehnert F, et al. In vitro differentiation characteristics of cultured human mononuclear cells-implications for endothelial progenitor cell biology. Biochem Biophys Res Commun 2005;333:476-82.

18. Kong Z, Hong Y, Zhu J, et al. Endothelial progenitor cells improve functional recovery in focal cerebral ischemia of rat by promoting angiogenesis via VEGF. J Clin Neurosci 2018;55:116-21.

19. Zengin E, Chalajour F, Gehling UM, et al. Vascularwall resident progenitor cells: a source for postnatal vasculogenesis. Development 2006;133:1543-51.

20. Qiu Y, Zhang C, Zhang G, et al. Endothelial progenitor cells in cardiovascular diseases. Aging Med (Milton) 2018;1:204-8.

21. Assmus B, Schachinger V, Teupe C, et al. Transplantation of progenitor cells and regeneration enhancement in acute myocardial infarction (TOPCARE-AMI). Circulation 2002;106:3009-17.

22. Bhatwadekar AD, Duan Y, Korah M, et al. Hematopoietic stem/progenitor involvement in retinal microvascular repair during diabetes: Implications for bone marrow rejuvenation. Vision Res 2017;139:211-20.

23. Shao Y, Chen J, Dong L, et al. A protective effect of

Cite this article as: Kong $Z$, Chen $M$, Jiang J, Zhu J, Liu Y. A new method of culturing rat bone marrow endothelial progenitor cells in vitro. Cardiovasc Diagn Ther 2020;10(5):1270-1279. doi: 10.21037/cdt-20-536
PPAR $\alpha$ in endothelial progenitor cells through regulating metabolism. Diabetes 2019;68:2131-42.

24. Banno K, Yoder MC. Tissue regeneration using endothelial colony-forming cells: promising cells for vascular repair. Pediatr Res 2018;83:283-90.

25. Cavalcante SL, Lopes S, Bohn L, et al. Effects of exercise on endothelial progenitor cells in patients with cardiovascular disease: A systematic review and metaanalysis of randomized controlled trials. Rev Port Cardiol 2019;38:817-27.

26. Liu Z, Wang W, Yang XQ, et al. Effect of Prescription Tongxin on Endothelial Progenitor Cells in Peripheral Blood. Altern Ther Health Med 2020;15:AT5960.

27. Joo HJ, Song S, Seo HR, et al. Human endothelial colony forming cells from adult peripheral blood have enhanced sprouting angiogenic potential through up-regulating VEGFR2 signaling. Int J Cardiol 2015;197:33-43.

28. Davis GE, Senger DR. Endothelial extracellular matrix: biosynthesis, remodeling, and functions during vascular morphogenesis and neovessel stabilization. Circ Res 2005;97:1093-107.

29. Liew A, O'Brien T. Isolation of Endothelial Progenitor Cells (EPCs). In: Slevin M, McDowell G, editors. Handbook of Vascular Biology Techniques. Dordrecht: Springer Netherlands, 2015:45-54.

30. Alphonse RS, Vadivel A, Zhong S, et al. The isolation and culture of endothelial colony-forming cells from human and rat lungs. Nat Protoc 2015;10:1697-708.

(English Language Editors: K. Brown and J. Reynolds) 